The telephones recommended are equipped with powerful magneto-generators and high-resistance bells, enabling a number to be bridged across one pair of wires if desired. They are fitted with 'neophone' hand-microtelephones to improve speech transmission. Portable telephones are provided for by 'looping in' one pair of wires at each point and fixing a 2-pin weatherproof socket. A lamp calling- system in addition to the bell can be fitted when the telephone is to be used in a very noisy position.

A.R.P. signals can be either visual or audible or a combination of both. The signal system usually consists of a starting switch which puts into action loud-ringing bells, hooters, etc., where large staffs are to be controlled, and buzzers or single lamps for offices and small staffs.

\title{
AN EXPERIMENT IN BIOLOGICAL CONTROL
}

$\mathrm{T}$ HE control of injurious forms of insect life by the application of biological methods has, in a number of instances, proved remarkably successful. Other methods of control in such cases had been of little avail or were impracticable. Success achieved by the utilization of the natural enemies of injurious insects has usually proved to be relatively inexpensive and of a more or less permanent character. As a rule the most favourable conditions are those afforded by tropical or subtropical islands where the dissemination of the beneficial introduced insects meets with few handicaps or barriers. Recently an experiment in the biological control of coconut pests in Seychelles has been recounted (Bull. Entomol. Res., 31 ; 1940).

The author of the paper in question, Mr. D. VeseyFitzgerald, mentions that the affected crop is of special importance, since its product, copra, is the main export of Seychelles. The pests concerned are scale insects (Coccidæ), and of these, four species were specially injurious. It is noteworthy that the species in question, namely, Ischnaspis longirostris, Pinnaspis buxi, Chrysomphalus ficus and Eucalymnatus tessellatus, are unknown as major pests of coconut in other countries, while the brown scales, that are usual pests of this crop, are not found in Seychelles. Other Coccidæe were also found to be infesting coconut in this area, while a large variety of different species were noted as attacking the general vegetation.
This fauna needed investigation, as it concerned the main problem, and as a result it became evident that general rather than specialized enemies of Coccidæ required searching for. Species that would, in fact, attack all the different scale insects without special preference were obviously needed, since the elimination of a particular kind might result in an increase of some other species. The life-history and special requirements of each of the four species, already named, are described and their incidence on the coconut is discussed.

In order to combat these Coccidæ, four species of Coccinellid beetles were introduced from East Africa. The species were Chiloconus distigma, C. wahlbergi, Exochomus ventralis and $E$. flavipes. Since the journey from Mombasa to Seychelles takes only three days by steamer, these predators could be landed there within a week of leaving the centres where they were bred in East Africa.

The breeding technique and the establishment of each of these species is dealt with. Records covering three years are given in order to show the effects of the introduced predators on the population of scale insects. The figure quoted shows that the introduced enemies are reducing the scale insects below the density at which they cause economic loss. Also it seems that the reduction of one species of pest has not been followed by a correlated increase of another species.

\section{ELECTRICITY IN AGRICULTURE}

$\mathrm{R}$ EFERENCE has already been made in NATURE (Jan. 11, p. 62) to the report on the utilization of electricity in agriculture and horticulture prepared by C. A. Cameron Brown and issued by the Electrical Research Association. The Institution of Electrical Engineers is now publishing written contributions to the discussion of this report. The first contribution appears in the Institution's Journal of November.

Mr. H. W. Grimmitt, of the staff of the Electricity Commissioners, begins his written introduction to the discussion by pointing out that the extent of the bibliography is some indication of the wideness of the field of research and investigation which was carried out. Great Britain has not been in the forefront of research into agricultural applications of electricity, but the small amount of work that has been done has indicated the need for a central co-ordinating body, with vital interest in the whole matter, to make use of the excellent agricultural research resources which already exist, and which, with proper help, could carry out research along the parallel and related paths of electricity and agriculture. The E.R.A. has taken steps to provide co-ordination and drive, and there is evidence of enthusiastic co-operation from the agricultural research institutions and also from the Ministry of Agriculture and the Agricultural Research Council. As a preliminary to active research, the E.R.A. has had prepared a complete survey of the whole field of research on the subject, both to provide information on past work and to make constructive suggestions for future work.

The general lines of the work are to investigate by research and experiment the extent to which each application of electricity can be developed to the point of maximum economic advantage to both farmer and supplier, and generally to study each application with the view of indicating the best technique to be adopted.

To the dairy farmer-the producer of milk and its by-products-more than to any other kind of farmer, electricity has much to offer. The appreciable load and annual revenue obtainable from a wellelectrified dairy farm are sufficient justification for some trouble being taken to show grounds why electrification should not be the rule instead of the exception. War conditions, scarcity of labour, higher 